\title{
OUTDOOR LIGHTING IN TUCSON: A PHOTO RECORD
}

WILLIAM T. ROBINSON

Robinson \& Associates, Tucson, AZ U.S.A.

ABSTRACT Photographic documentation of outdoor lighting installations has been underway in Tucson and throughout Arizona for some time. Such photos show what can be done to minimize the problem of light pollution, illustrating examples of both good and bad lighting designs and installations. Copies of such photos (mostly in the form of slides) are available from the International Dark-Sky Association. 